\title{
VERPLEEGLEIERSKAP 'n Teoretiese Perspektief
}

\author{
E.M. JACOBS
}

Geregistreerde Algemene en Psigiatriese Verpleegkundige en Vroedvrou,

B.A. Cur (Hons) (Unisa).

Hoofverpleegkundige, Sterkfontein-hospitaal

\section{SUMMARY}

Nursing leadership is one of the current issues in nursing administration. It is generally accepted that when a person holds a key position he is automatically also a leader. This is a misconception as it has become evident that managers are not always leaders and vice versa.

In the past leadership was associated with aggression, male characteristics and domination, while passivity was associated with women. It is evident that this is not the case and that there is no specific theory of leadership which can be recommended.

Leaders are never only people orientated or only task orientated but leadership usually includes components of both. There are also many factors influencing leadership such as personality, situations, objectives, environments and the level of maturity of the followers. It is recommended that a leader adapts his leadership style to the situation and acts according to the demands of the problem — in other words, applying situational leadership.

\section{INLEIDING}

Verpleegleierskap word as een van die dringendste kwessies van ons tyd beskou. Verpleegadministrators moet hulself bewustelik vir leierskaprolle voorberei en moet besef dat dit ' $n$ wetenskaplike proses is, net soos verpleegkunde self, en wetenskaplike kundigheid en leierskap vermoëns vereis $(9: 67)$.

Daar is 'n duidelik waarneembare behoefte aan verpleegleierskap op elke terrein van verpleegkunde. Verpleegkundiges behoort almal leiers te wees, omdat hulle in die kliniese area die kliënt tot optimale gesondheid moet lei. Die verpleegadministrator moet personeel tot optimale funksionering, en die verpleegonderwyser moet studente tot toekomstige leiers kan lei.

Leierskap is dus nie net vir verpleegadministrators nie, maar vir elke individuele verpleegkundige (8:5).

Wêreldwyd is verpleegkundiges besorgd oor die feit dat daar 'n tekort aan verpleegleiers is. Alhoewel baie verpleegkundiges leierskapsposisies beklee, is baie min werklik betrokke in gesondheidsorg besluitneming. Dit kan wees omdat verpleegkundiges 'n baie lae selfwaarde het wat hulle leierskapsvaardighede betref (8:5).

\section{LEIERSKAP TEENOOR BESTUUR}

Oor die algemeen bestaan daar verwarring tussen die begrippe leierskap en bestuur, of administrasie (8:11).

Individue wat bestuursposisies beklee, is ook leiers, maar daar mag diegene wees wat glad nie leiers is nie en alleenlik op hulle posisies staatmaak om resultate te verkry. In die meeste gevalle word outoriteit en leierskap met mekaar verbind. Die rede waarom bestuurders wat nie leiers is nie, suksesvol is, is omdat hulle outoriteit en leierskap kombineer, waar sommige net op outoriteit staatmaak. Dit is dus duidelik dat leierskap en bestuur nie sinoniem is nie.

Daar is baie leiers wat nooit in 'n verpleegadministrasie pos sal belangstel nie. Daar moet dus duidelik verstaan word dat 'n verpleegadministrator in 'n hoë pos nie vanselfsprekend as 'n leier gesien moet word nie. Dikwels het hierdie persone geen of min leiereienskappe $(8: 11)$.
Bestuurders is beter bestuurders indien hulle ook leiers is $(2: 2)$.

\section{LEIERSKAP: 'N BEGRIPSOMSKRYWING}

Douglas en Bevis $(2: 2)$ beweer dat leierskap 'n aangeleerde gedragspatroon is. Die feit dat sekere persoonlikheidskenmerke die ontwikkeling van natuurlike leierskap bevorder word deur hulle erken, maar in die hedendaagse komplekse struktuur is meer as net persoonlikheidskenmerke nodig om 'n leier te wees.

Leierskap is 'n stel aksies wat lede van 'n groep beïnvloed om doelwitte te bereik (2:2). Leierskap kan ook definieer word volgens gedrag wat deur leiers openbaar word, maar ook dit is nie genoeg nie $(2: 2)$.

Moloney ( $8: 10)$ is van mening dat leierskap 'n proses is waardeur die aktiwiteite van 'n groep beïnvloed word tot bereiking van doelstellings. Die meeste navorsers beskou leierskap as 'n proses en die fokus berus op optrede om ander te beïnvloed tot bereiking van doelstellings (8:11). 
Deep (3:65) meld dat leierskap die persoonlike begeleiding van ondergeskiktes is tot die bereiking van die doelwitte van 'n instelling. Dit word gedoen deur voorskrifte aan die individu, erkenning van sy behoeftes en verteenwoordiging van ondergeskiktes op hoër vlakke waar hulle nie vir hul self kan praat nie. Die invloed van die leier op ondergeskiktes is die sleutel tot leierskap, maar dit hang af van die mag wat aan die leier toegeken is (3:65). A Good Leader is someone who can step on your toes, without messing up your shine (3:65).

Volgens Deep (3:66), was Eisenhower se omskrywing van leierskap, The ability to decide what has to be done, and then to get others to want to do it (3:70). Dit is duidelik dat outeurs voel dat leiers invloed op mense moet hê om effektiewe leiers te wees.

Searle (9:67) meld dat leierskap dui op vertroue in die saak, verwagtinge, beplanning, strategie, multidimensionele verantwoordelikheid, uitdaging en die geleentheid en dryfkrag om 'n gesonde toekoms vir verpleging te bou. Leierskap is egter ' $n$ aangeleerde gedragspatroon.

Alle outeurs is dit egter eens dat leierskap ' $n$ proses is waardeur mense gelei word om 'n gemeenskaplike doelwit te bereik.

\section{LEIERSKAP TEORIEË}

Daar word algemeen aanvaar dat daar drie benaderings is in die bestudering van leierskap, naamlik:

- persoonlikheidseienskappe benadering

- gedragsbenadering

- situasiebenadering

Leierskap is 'n komplekse verskynsel en om leierskapsgedrag te verstaan is moeilik. Die leierskapsbenadering wat deur 'n leier gebruik word, kan sy effektiwiteit as 'n leier beïnvloed.

\section{Persoonlikheidseienskappe benadering}

Tot onlangs is leierskap primêr in terme van persoonlikheidseienskappe van 'n persoon gesien. Daar is egter geglo dat leiers aangebore eienskappe het en dat min persone oor hierdie kwaliteite beskik (8:22).

Hierdie teorie lê klem op die feit dat daar sekere persoonlikheidseienskappe vir 'n effektiewe leier is. Dit het ontstaan uit die Great Man Theory wat sy oorsprong in die 19 de eeu het, toe gesê is dat 'n leier superior kwaliteite het wat hom van ander mense onderskei. Daar is geglo dat wanneer hierdie eienheidseienskappe gedefinieer wat eie persoon opgelei kan word om 'n leier te wees $(4: 21)$.

Volgens Heimann (4:21) het 'n sekere navorser, sekere persoonlikheidseienskappe gedefinieer wat eie behoort te wees aan ' $n$ leier, onder andere:

- 'n dinamiese fisiese voorkoms

- simpatie, begrip en vriendelikheid

- behulpsaamheid en vriendelikheid is belangriker as vaardigheid

- moet onafhanklike oordele kan maak

- moet soms eerder die simptome van die probleem verstaan as die oorsaak

- moet buigsaam wees

- moet ondervinding en selfvertroue hê

— moet 'n egalige temperament hê

- moet kan organiseer.

Nog 'n navorser, ene Tead (4:21), het ook sekere eienskappe voorgestel, naamlik 'n leier:

- moet meer fisiese en psigiese energie as 'n gewone persoon, hê, omdat leidinggewing 'n moeilike taak is

- moet die doelstellings en doelwitte van die groep en van die instelling ken

- moet entoesiasme van die groep kan kweek

- moet vriendelik en intelligent wees

- moet besluite met behulp van wetenskaplike metodes kan maak

- moet buigsaam wees met 'n goeie humorsin

- moet meer 'n onderwyser wees om mense te kan lei

- moet 'n geloof in mense en ' $n$ sin en betekenis in die lewe hê.
Hierdie persoonlikheidseienskappe word nie langer alleen aanvaar nie en word nie alleen as geldig aanvaar nie. Baie leiers het nie hierdie eienskappe nie en is tog suksesvol, soos Hitler, wat 'n uitstekende leier was, sonder integriteit en vriendelikheid (4:22). Aan die ander kant het mense hierdie kwaliteite en is nie effektiewe leiers nie. Hierdie benadering is nie geldig nie omdat dit nie die sukses of onsuksesvolheid van leiers kan verklaar nie. Leierskap moet dus iets meer behels as net persoonlikheidseienskappe.

\section{Gedragsbenadering in Leierskap}

Hierdie benadering beklemtoon die gedragsdimensies wat gebruik kan word in leierskap. Die klem val met ander woorde op verskillende gedragwyses wat 'n persoon kan openbaar. Dit gaan dus nie om persoonlike eienskappe nie, maar oor die wyse waarop mense gelei kan word (8:23).

Dit verskil van die persoonlikheidseienskappe benadering in die sin dat gedrag waarneembaar is, met ander woorde, wat doen die leier en hoe tree hy op, en nie wat is die leier nie.

Die persoonlikheidsbenadering neem ook nie in aanmerking dat ondergeskiktes of volgers behoeftes het nie, of dat persoonlikheid en situasies leierskap kan beïnvloed nie (8:23).

Die gedragsbenadering in leierskap word vervolgens bespreek.

\section{Outokratiese Leier}

Dit word ook deur sommige outeurs bespreek as die Scientific management approach (8:24). Dit kan ook direktiewe leierskap genoem word en impliseer dat 'n leier bevele gee en verwag dat dit sonder aarseling of argumente uitgevoer word $(8: 24)$. Hierdie leiers beklemtoon die werk wat gedoen moet word en het ' $n$ dominerende en bevelende houding. Sy mag word op die outoriteit van sy posisie baseer. 
Die atmosfeer in die outokratiese leierskap omgewing word gekenmerk deur dominering deur die leier en vermindering van vryheid van beweging van die volgers of ondergeskiktes. Daar is gewoonlik spanning in hierdie situasie teenwoordig (8:25), omdat die klem op die sisteem en die werk en minder op die behoeftes van die kliënt is.

Besluite word deur die leier gemaak en daar is minimale deelname in besluitneming van ander lede. Daar word gevoel dat personeel in so 'n situasie gefrustreerd raak en dat moreel verlaag $(2: 247)$. Personeel is gewoonlik bang om inisiatief te gebruik of om opinies te lug.

\section{Demokratiese Leierskap}

Hierdie leiers laat toe dat hulle ondergeskiktes deelneem aan die besluitnemingsproses, en dit is een van die mees populêre leierskapsbenaderings.

Leiers moedig die groep aan om besluite te neem of om daaraan deel te hê, terwyl die leier self die finale besluite neem. Dit impliseer nie dat die groep die doelwitte stel en die besluite neem nie, soos wat deur sommige outeurs gedink word nie. Die groep neem deel maar die finale besluite berus by die leiers $(8: 26)$.

Daar moet egter duidelik verstaan word dat alleen groepslede met die nodige kennis en ondervinding toegelaat word om aan die besluitnemingsproses deel te neem.

Daar is bewys dat hierdie benadering in leierskap meehelp om werkbevrediging te verbeter, moraal te verhoog en griewe en vyandigheid teenoor die leier te laat verminder $(8: 26)$.

Die onderliggende benadering in hierdie leierskapstyl is dat die ondergeskiktes gemotiveer word tot selfgerigtheid, selfverwesenliking en skeppende werksverrigting. Die leier stimuleer die groep om die oplossings te vind en om so in hulle behoeftes te voorsien. Dit gebeur dat mense sê dat hulle alles self gedoen het, sonder dat hulle bewus was van die feit dat hulle deur iemand anders gelei is (8:27).
Daar word geglo dat hierdie leier die samewerking van mense koop deur hulle toe te laat om deel te neem aan besluitneming en in ruil daarvoor, hoop dat hulle sal saamwerk om hierdie besluite uit te voer en die doelwitte te bereik.

Hierdie styl mag soms ook nie effektief wees nie as gevolg van krisisse wat mag ontstaan en gebrek aan belangstelling by volgers om aan besluitneming deel te neem (8:27).

Dit word ook die deelnemende leierskapstyl genoem.

\section{Laissez-Faire Leier}

By hierdie leierskapstyl het die groep die vryheid om te funksioneer en om self doelwitte te stel, onafhanklik van die leier.

Vir 'n tyd mag die groep soveel vryheid geniet, maar daarna raak hulle frustreerd en gespanne, verward en ontevrede om sonder 'n leier te funksioneer.

Sommige outeurs beskryf dit nie as 'n leierskapstyl nie maar beskou dit as 'n afwesigheid van leierskap (8:29). 'n Persoon wat 'n groot behoefte aan aanvaarding by die groep het mag hierdie leierskapstyl gebruik. Die leier wil dus almal tevrede stel en kan in die proses nie leiding gee nie $(2: 248)$.

\section{Instrumentele Leier}

Dit impliseer dat die leier gesteld is op resultate en dat min ondersteuning aan die groep gebied word (8:29).

Hulle is gedurig besig om die aktiwiteite van die groep te organiseer, kontroleer, beplan en te koördineer. Die klem is dus op die kontrolering van resultate en materieële hulpbronne.

Hierdie leiers mag 'n outokratiese of ondersteunende styl aanneem, maar die klem bly op die taak wat uitgevoer moet word en die kontrole van die hulpbronne, onder andere toerusting $(8: 29)$.

\section{Great Man Leier}

Hierdie benadering is gebaseer op die geloof dat mense kan leer deur die bestudering van die lewens van groot manne. Hulle kan hulle lewens vergelyk, en geïnspireer word deur hierdie persone wat in die verlede beroemdheid verwerf het.

Aanhangers van hierdie teorie glo dat effektiewe leierskap 'n kombinasie is van deelnemende en instrumentele leierskap. Individue wie albei hierdie eienskappe besit is skaars en word na verwys as, die Groot Man (Great Man Leader) (6:12).

Dit word beskou as 'n effektiewe leierskapstyl in alle situasies (6:12).

Omdat hierdie teorie impliseer dat leiers gebore word en nie gemaak word nie, word dit as onaantreklik beskou. Dit sou meer aanvaarbaar wees as dit sou impliseer dat leiers ontwikkel word.

\section{Twee Dimensionele Leier}

Hier spesifiseer die leier die werk wat gedoen moet word en die doelstellings wat bereik moet word, en evalueer die werksverrigting van die werknemer. Hy stel ook terselfdertyd belang in die individu se behoeftes en bied warmte, ondersteuning en vriendskap.

Sommige leiers beklemtoon egter net die werk terwyl ander albei hierdie dimensies noodsaaklik vind (8:30). Hierdie dimensies kan dus as aparte leierskapstyle gesien word.

Navorsers beklemtoon vier belangrike eienskappe in hierdie styl, naamlik:

- besorgdheid vir ander

— inisiëring van struktuur vir ondergeskiktes

- produktiwiteit as voorbeeld vir ander

- sensitiwiteit en aanvaarding vir ander (8:30).

\section{Path Goal Teorie}

Die leier tree op omdat hy verwag sy gedrag gaan bevredigende resultate lewer. Hy verwag dat take gedoen gaan word met die minimum obstruksie en dat die volgers erkenning moet kry wanneer die taak voltooi is. Hierdie leier is dus ook meer taak-geörienteerd en persone met 'n behoefte aan erkenning sal hierdie leier verkies $(6: 116)$. 


\section{Lewenssiklus Teorie}

\section{(Life-Cycle Theory)}

Volgens navorsers (6:116) impliseer hierdie model dat 'n persoon met toenemende volwassenheid beweeg vanaf passiwiteit na aktiwiteit en van afhanklikheid na interafhanklikheid.

Die leier moet dus aapas by die volwassenheidsvlak van die groep en moet sy leierskapstyl aanpas.

\section{Situasie Leierskap (Situational Leadership Theory)}

Die nuutste benadering in leierskap is die situasie leierskapsteorie wat impliseer dat die situasie sal bepaal watter gedrag gevolg sal word. Leierskap word beskou as 'n dinamiese proses wat variëer van situasie tot situasie en 'n effektiewe leier is een wat aanpasbaar is.

Die belangrikste bestanddele is die leier, die volger en die situasie (8:31).

Volgens Tyndall (10:26) is dit 'n eklektiese benadering, met ander woorde, dat geen leierskapstyl gepas is vir elke mens in alle situasies nie. Die leier tree afhangende van die situasie op en dit is dus probleemoplossing geörienteerd. Eklekties impliseer dat daar leierskapsgedrag uit elke teorie geneem word om by die situasie aan te pas.

Daar is drie hoofkonsepte wat verstaan moet word alvorens hierdie leierskapstyl begryp kan word, naamlik:

- die vermoë van die leier om doelwitte te stel wat bereikbaar is

- struktuering van die werk wat gedoen moet word

- die verhouding van die leier tot ondergeskiktes met inagneming van menslike behoeftes.

By hierdie teorie sal die leier dus nie 'n spesifieke leierskapsgedrag openbaar nie, maar sal optree soos wat die situasie (10:26) vereis. Die leier pas dus an by die gegewe situasie. Soms sal die persoon 'n outokratiese leier wees waar hy alleen besluite sal neem, en soms sal hy demokraties wees, waar groepslede mag deelneem aan besluitneming.

Daar is verskeie veranderlikes wat in aanmerking geneem moet word by die keuse van 'n leierskapstyl, onder andere die volwassenheid van die groep en die verhouding tot die spesifieke taak wat uitgevoer moet word (10:28).

\section{TOEPASSING VAN LEIER- SKAP IN DIE VERPLEEG- KUNDE PRAKTYK}

Leierskap is reeds gedefinieer as 'n dinamiese (8:86), aanpasbare, interaksionele proses wat beteken dat daar beweging is na verandering binne 'n stelsel. Om te lei beteken om verandering teweeg te bring en om werkers te lei om na 'n spesifieke doelwit te werk. Dit is interaksioneel omdat dit die aksie van individue impliseer. Leiers is nie die enigste komponent in die leierskapsproses nie. Sonder 'n groep wat gelei moet word kan die leier nie bestaan nie (8:88) omdat leierskap binne ' $n$ sisteem interaksie insluit.

In die verpleegkundige-pasiënt verhouding is interaksie essensiëel en dit verwys na werklike of waargenome gedrag tussen twee of meer individue. Vir enige interaksie moet daar minstens twee persone teenwoordig wees.

Die belangrikste aspekte van leierskap in die praktyk word vervolgens bespreek.

\section{Die terapeutiese self}

Elke verpleegkundige-pasiënt of verpleegleier-volger verhouding moet wedersydse begrip vir mekaar weerspieël. Elke leier moet eerstens homself ken, verstaan en aanvaar en die nodige selfvertroue ontwikkel om ander te aanvaar en te lei (8:90). Die leier moet dus sy eie persoonlikheid analiseer en aanvaar en dan daardie persoonlikheid konstruktief gebruik om ander te begelei.

\section{Vertrouensverhouding}

Om 'n persoon te help om homself te kan help moet die verpleegleier 'n vertrouensverhouding opbou, gebaseer op wedersydse respek, aanvaarding, begrip en empatie.

\section{Kommunikasie}

Die verpleegleier moet gebruik maak van verbale en nie-verbale kommunikasie om haar belangstelling, besorgdheid en begrip oor te dra aan die individue met wie sy in interaksie tree $(8: 90)$.

Kommunikasie voorsien die instrument waardeur kliente beïnvloed word tot werkverrigting en waardeur begeleiding verskaf word. Woorde moet dus versigtig gekies word, sodat die regte boodskap oorgedra word. Dit geld ook vir die nie-verbale boodskap (deur liggaamstaal en houding).

Die luisterkuns gaan gepaard met kommunikasie, 'n vaardigheid wat moeilik is, maar met gereelde oefening geslaagd sal wees. Hierdeur word egtheid aan die kliënt oorgedra. Die persoon kry die gevoel dat iemand verstaan en weet wat, en hoe hy voel. Om te luister is dus 'n kuns wat geoefen moet word.

\section{Motivering}

Hierdie is ' $\mathrm{n}$ belangrike aspek wat bydra tot die effektiwiteit van die leier. Leiers moet bewus wees van die basiese behoeftes van mense en waardeur mense tot werksverrigting en optrede motiveer word (1:25).

Individue het gedurig motivering nodig om hulle in staat te stel om hulle energie in 'n konstruktiewe rigting tot die bereiking van gestelde doelwitte te stuur (8:92).

Verpleegleiers moet benewens hulle kennis van menslike behoeftes, ook hulle motiveringsvaardighede ontwikkel.

Longest (5:156) is van mening dat daar twee noodsaaklike aspekte is wat deur die verpleegleier in die praktyk ontwikkel moet word, naamlik:

\section{Empatie}

Dit is die vermoë wat 'n persoon moet ontwikkel om homself in die posisie van iemand anders te kan plaas, om te verstaan of probeer verstaan hoe 'n ander persoon voel, om hulle waardes en norme te probeer begryp. Die leier sonder empatie, neem vanselfsprekend aan dat sy ondergeskiktes dieselfde waardes en ambisies as hyself het. Die leier behoort homself gedurig af te vra hoe hy sou optree indien hy in 'n soortgelyke posisie as sy volger sou wees $(5: 156)$.

\section{Vervolg op P56}

